\title{
Chemogenetic Inhibition of Infralimbic Prefrontal Cortex GABAergic Parvalbumin Interneurons Attenuates the Impact of Chronic Stress in Male Mice
}

\author{
(D)Nawshaba Nawreen, ${ }^{1,2,4}$ Evelin M. Cotella, ${ }^{1,4}$ Rachel Morano, ${ }^{1}$ Parinaz Mahbod, ${ }^{1}$ Khushali S. Dalal, ${ }^{3}$ \\ Maureen Fitzgerald, ${ }^{1}$ Susan Martelle, ${ }^{1}$ Benjamin A. Packard, ${ }^{1,4}$ Ana Franco-Villanueva, ${ }^{1}$ \\ Rachel D. Moloney, ${ }^{1,4}$ and James P. Herman ${ }^{1,2,4,5}$
}

https://doi.org/10.1523/ENEURO.0423-19.2020

${ }^{1}$ Department of Pharmacology and Systems Physiology, University of Cincinnati, Cincinnati, OH 45237-0506, ${ }^{2}$ Neuroscience Graduate Program, University of Cincinnati, Cincinnati, OH 45237-0506, ${ }^{3}$ College of Allied Health Sciences, University of Cincinnati, Cincinnati, $\mathrm{OH} 45237-0506,{ }^{4}$ Veterans Affairs Medical Center, Cincinnati, $\mathrm{OH}$ 45221-0506, and ${ }^{5}$ Department of Neurology and Rehabilitation Medicine, University of Cincinnati, Cincinnati, $\mathrm{OH}$ 45237-0506

\begin{abstract}
Hypofunction of the prefrontal cortex (PFC) contributes to stress-related neuropsychiatric illnesses. Mechanisms leading to prefrontal hypoactivity remain to be determined. Prior evidence suggests that chronic stress leads to an increase in activity of parvalbumin (PV) expressing GABAergic interneurons (INs) in the PFC. The purpose of the study was to determine whether reducing PV IN activity in the Infralimbic (IL) PFC would prevent stress-related phenotypes. We used a chemogenetic approach to inhibit IL PFC PV INs during stress. Mice were first tested in the tail suspension test (TST) to determine the impact of PV IN inhibition on behavioral responses to acute stress. The long-term impact of PV IN inhibition during a modified chronic variable stress (CVS) was tested in the forced swim test (FST). Acute PV IN inhibition reduced active (struggling) and increased passive coping behaviors (immobility) in the TST. In contrast, inhibition of PV INs during CVS increased active and reduced passive coping behaviors in the FST. Moreover, chronic inhibition of PV INs attenuated CVS-induced changes in Fos expression in the prelimbic cortex (PrL), basolateral amygdala (BLA), and ventrolateral periaqueductal gray (vIPAG) and also attenuated adrenal hypertrophy and body weight loss associated with chronic stress. Our results suggest differential roles of PV INs in acute versus chronic stress, indicative of distinct biological mechanisms underlying acute versus chronic stress responses. Our results also indicate a role for PV INs in driving chronic stress adaptation and support literature evidence suggesting cortical GABAergic INs as a therapeutic target in stress-related illnesses.
\end{abstract}

Key words: DREADDs; GABA; interneurons; parvalbumin; prefrontal cortex; stress coping

\section{Significance Statement}

Stress-related diseases are associated with prefrontal hypoactivity, the mechanism of which is currently not known. In this study we showed that by inhibiting prefrontal GABAergic parvalbumin interneurons (PV INs), we can attenuate some of the chronic stress-related phenotypes. Additionally, we showed that modulation of PV IN activity during acute stress had opposing effects on stress coping strategies, suggesting different plasticity mechanisms in PV INs following acute versus chronic stress. Our findings indicate that GABAergic PV INs may be involved in driving stress-related phenotypes and may therefore be an important target for treatment of stress-related illnesses. Our data suggest that reducing PV IN activity to promote prefrontal output may be a potential treatment strategy for stress-related disorders. 


\section{Introduction}

Mood disorders [e.g., posttraumatic stress disorder (PTSD) and major depressive disorder (MDD)] are associated with alterations in ventromedial prefrontal cortex (PFC; Broadman area 25) structure, activity and connectivity (Rogers et al., 2004; Drevets et al., 2008; Hasler et al., 2008; Murray et al., 2011; Holmes et al., 2018). To date, no universally efficacious therapeutic strategy exists for these neuropsychiatric conditions, despite having a lifetime prevalence of over 20\% (Kessler et al., 2005; Duman and Duman, 2015). Studies in both humans and animal models have shown that chronic stress impairs functioning of the PFC, potentially making prefrontal hypofunction an important factor in the etiology of mood disorders (Drevets et al., 1997; Radley et al., 2006; Duman and Duman, 2015; Li et al., 2011; McKlveen et al., 2016).

Various clinical and preclinical studies implicate altered GABAergic circuitry and prefrontal hypofunction in the generation of depression in humans as well as depression-related behaviors in rodent chronic stress models (Luscher et al., 2011; Duman, 2014; Veeraiah et al., 2014; Musazzi et al., 2015; McKlveen et al., 2016). Recent functional and electrophysiological studies indicate increased infralimbic (IL) PFC (rodent homolog of the human ventromedial PFC) GABAergic transmission (e.g., increased inhibitory synaptic drive and increased expression of GABAergic marker) following chronic variable stress (CVS). These findings suggest that enhanced interneuron (IN) activity may be involved in disruption of prefrontal cortical signaling, leading to over inhibition and prefrontal hypofunction (McKlveen et al., 2016; Shepard et al., 2016; Page et al., 2019).

GABAergic parvalbumin INs (PV INs) synapse onto cell bodies of PFC pyramidal neurons and exert strong control over medial PFC (mPFC) output, maintaining appropriate excitatory/inhibitory (E/I) balance (Cardin et al., 2009; Courtin et al., 2014a; Tremblay et al., 2016) and coordinating oscillatory activity ( $\gamma$ oscillation) required for

Author contributions: N.N., E.M.C., S.M., R.D.M., and J.P.H. designed research; N.N., R.M., P.M., K.S.D., M.F., and B.A.P. performed research; N.N. and A.F.-V. contributed unpublished reagents/analytic tools; N.N., E.M.C., and K.S.D. analyzed data; N.N. and J.P.H. wrote the paper.

This work was supported by National Institute of Mental Health (NIMH) Grants R01-MH101729 and R01-MH048698 and by the United States Department of Veterans Affairs Grant I01BX003858 (to J.P.H.), NIMH Grants T32-NS-007453 and F31- MH123041 (to N.N.) and T32 DK059803 (to E.M.C.), Cohen Veterans Bioscience (S.M.), and a National Alliance for Research on Schizophrenia and Depression Young Investigator Award (R.D.M.).

S. Martelle's present address: Wake Forest Innovations, Wake Forest School of Medicine, Winston-Salem, North Carolina, United States.

R. D. Moloney's present address: School of Pharmacy, University College Cork, Cork, Ireland.

Acknowledgements: We thank Herman lab members for help with study conduct. We also thank Dr. Eric Wohleb and Dr. Mark Baccei for technical assistance, support, and discussion of the results. Figures for this manuscript were created with BioRender.com.

Correspondence should be addressed to James P. Herman at hermanjs@ ucmail.uc.edu.

https://doi.org/10.1523/ENEURO.0423-19.2020

Copyright (C) 2020 Nawreen et al.

This is an open-access article distributed under the terms of the Creative Commons Attribution 4.0 International license, which permits unrestricted use, distribution and reproduction in any medium provided that the original work is properly attributed. efficient PFC signaling. Consequently PV INs are well positioned to play an important role in stress-mediated prefrontal dysfunction (Rymar and Sadikot, 2007; Sherwood et al., 2007; DeFelipe et al., 2013; Ferguson and Gao, 2018). Increases in expression and activity of PV INs and enhancement of glutamatergic transmission onto PV INs following chronic stress are associated with prefrontal hypofunction, anxiogenesis, and impaired coping behaviors in forced swim test (FST) (Shepard et al., 2016; Page et al., 2018, 2019; Shepard and Coutellier, 2018). Reduction in PV expression in PFC is also associated with antidepressant efficacy (Ohira et al., 2013; Zhou et al., 2015; Page and Coutellier, 2019). In contrast to chronic stress, acute inhibition of PV INs in the PFC has opposing effects, resulting in increase in passive coping behavior such as learned helplessness in mice (Perova et al., 2015). This suggests differential role of PV INs in response to acute versus chronic stress, indicative of distinct brain circuitry being involved in modulating acute versus chronic stress-mediated phenotypes.

This study was designed to specifically investigate the role of IL PV INs in driving somatic and behavioral manifestations of acute and chronic stress-related phenotypes. We employed a chemogenetic strategy using designer receptors exclusively activated by designer drugs (DREADDs) to specifically inhibit PV INs in the IL mPFC during exposure to acute stress and throughout exposure to a modified CVS paradigm. Our results indicate that acute inhibition of PV INs increases passive and decreases active coping behavior in tail suspension test (TST). In contrast, chronic inhibition of IL PV INs reduces passive and increases active coping behavior in FST. PV IN inhibition attenuates CVS-mediated reduction in Fos expression in stress-related brain regions downstream of the IL. Additionally, we show that inhibition of PV INs prevents CVS-induced somatic effects such as adrenal hypertrophy and body weight loss. These data suggest that IL PV INs play a role in driving behavioral, neuronal and physiological adaptations associated with chronic stress and also indicate differential role of these INs in the context of acute versus chronic stress-related phenotypes.

\section{Materials and Methods}

\section{Mice}

Male breeders from B6 PV-Cre knock-in homozygous mice line (B6;129P2-Pvalbtm1(cre)Arbr/J, JAX stock \#017320, The Jackson Laboratory) were bred with WT C57BL/6J females (JAX stock \#000664) to generate an in-house colony of heterozygous PV-Cre C57BL/6J at the University of Cincinnati animal housing facility. The PV-Cre mouse line has been characterized extensively in prior publications (Zhao et al., 2019; Cummings and Clem, 2020; Groisman et al., 2020). Mice were maintained under standard conditions (12/12 h light/dark cycle, $22 \pm 1^{\circ} \mathrm{C}$, food and water ad libitum; four mice per cage on arrival) in accordance with the University of Cincinnati Institutional Animal Care and Use Committee, which specifically approved all acute and chronic stress regimens employed in this proposal. Mice were single housed following surgeries and continued to be housed singly throughout the duration of the experiment, to prevent aggression and injury to 
animals following surgery and during the stress paradigms (Lidster et al., 2019). Enrichment for housing cages included mouse hut and nestlets. All protocols conformed to the Society's Policies on the Use of Animals in Neuroscience Research. All experiments were performed on adult male mice ( $\sim 7.5$ months of age at surgery).

\section{Stereotaxic viral vector injection with $A A V$ vectors}

PV-Cre mice were anaesthetized with isoflurane, scalp shaved and placed in the stereotaxic frame. The incision site was disinfected using chlorohexidine and $70 \%$ ethanol. An incision at the midline was made using a singleedged blade. Cre-dependent adeno-associated virus 2 (AAV2) vectors AAV2-hsyn-DIO-hM4D(Gi)-mCherry (Gift from Bryan Roth; Addgene viral prep \#44362-AAV2) and AAV2-hsyn-DIO-mcherry (Gift from Bryan Roth; Addgene viral prep \#50459-AAV2) were injected bilaterally at a volume of $300 \mathrm{nl}\left(\sim 10^{12}\right.$ genome copies $\left./ \mathrm{ml}\right)$ into the IL mPFC. A pilot study was conducted (data not shown) to optimize viral load, volume and stereotactic coordinates to ensure viral spread is restricted to the IL. We specifically chose AAV serotype 2 , which has a limited volume of spread enabling us to primarily target the $\mathrm{IL}$ and prevent spread to other regions (Burger et al., 2004; Cearley and Wolfe, 2006). The coordinates used were as follows: (anterior/posterior range defined as $+1.78 \mathrm{~mm}$ anterior to bregma, medial-lateral range defined as $\pm 0.2 \mathrm{~mm}$ lateral to the midsagittal suture; dorsal-ventral range defined as $-2.9 \mathrm{~mm}$ ventral to skull (Franklin and Paxinos, 2007). Viruses were infused using a 2- $\mu$ l Hamilton syringe at a rate of $60 \mathrm{nl} / \mathrm{min}$ for $5 \mathrm{~min}$. To ensure that virus injection was restricted to bilateral spread in the IL, we took particular care at a few key points: (1) mouse skulls were always carefully vertically leveled based on bregma and $\lambda$ to ensure bilateral spread, (2) Hamilton syringes were always checked to run properly before injections and were carefully cleaned to remove excess virus particles after viral loading to prevent spread when the needle is lowered into the brain, (3) following infusion, the injector was kept at the site for $8 \mathrm{~min}$ to allow for the virus to diffuse and prevent spread to other regions, and (4) after injection, the needle was very slowly removed from the injection site to avoid spreading of the virus throughout the injector. The injection site on the skull was covered with gel foam and incision site sutured; $2.5 \mathrm{mg} / \mathrm{kg}$ meloxicam was administered for $3 \mathrm{~d}$ following surgery. Behavioral studies and stress protocols were initiated three weeks post injection to allow sufficient time for viral expression. Diagrammatic representation of experimental timeline is outlined in Figure $1 A$.

\section{Modified CVS procedure}

During the CVS procedure, mice were subjected to a series of randomly alternating stressors administered twice daily over a period of $14 \mathrm{~d}$. The CVS procedure used in this study is a modification of prior published protocols from the literature (Ostrander et al., 2009; Ghosal et al., 2017; Wohleb et al., 2018; Cotella et al., 2019), such that each individual stress session did not last for $>2 \mathrm{~h}$ to ensure that $\mathrm{CNO}$ was on-board throughout the stressor (Jendryka et al., 2019). CNO has been shown to reach maximal plasma levels $30 \mathrm{~min}$ after intraperitoneal injection and has been shown to rapidly clear from plasma in rodents (Baldessarini et al., 1993; Guettier et al., 2009; MacLaren et al., 2016; Jendryka et al., 2019). As a result, extended stress periods and overnight stressors typically used in CVS paradigms were excluded from the modified CVS paradigm. Additionally, swim stress was not included in the CVS paradigm since animals were tested in FST (a novel stressor) following completion of the CVS procedure. The unpredictable stressors used were as follows: restraint (30 min), cold room exposure $\left(15 \mathrm{~min}, 4^{\circ} \mathrm{C}\right)$, shaker stress ( $1 \mathrm{~h}, 100 \mathrm{rpm}$ ), hypoxia (30 min, $8 \%$ oxygen and $92 \%$ nitrogen), $Y$ maze $(8 \mathrm{~min})$, shallow water (30 min), wet bedding ( $2 \mathrm{~h})$, and cage tilt $\left(2 \mathrm{~h}, 45^{\circ}\right)$. Body weights were measured on days $1,4,8$, and 14 during the CVS procedure.

\section{Drug administration}

Clozapine N-oxide (CNO; NIMH Chemical synthesis and Drug Supply Program) was used as the DREADD actuator to activate the inhibitory DREADD. CNO was dissolved in 5\% dimethyl sulfoxide (Sigma) and then diluted with $0.9 \%$ saline and administered intraperitoneally at a dose of $1 \mathrm{mg} / \mathrm{kg}$ twice a day, $30 \mathrm{~min}$ before start of each stressor. We chose intraperitoneal injections for CNO delivery to effectively control the dose and timing of DREADDs during our stress paradigm. All animals received chronic injection of CNO for $14 \mathrm{~d}$. Previous work has shown that chronic CNO for $14 \mathrm{~d}$ does not lead to desensitization of hM4Di DREADDs, confirming efficacy of chronic activation of DREADDs (Soumier and Sibille, 2014; Xia et al., 2017; Stedehouder et al., 2018; Phillips et al., 2019). A maximum time period of $6 \mathrm{~h}$ was given between stressors, to allow sufficient time for CNO to be cleared from the body (MacLaren et al., 2016; Jendryka et al., 2019). To ensure inhibiting PV INs had no effects on locomotor activity, total distance traveled and velocity of mice was measured during $Y$ maze task on day 12th of the CVS regimen.

\section{Behavioral assessments \\ TST}

The TST (Can et al., 2011) was used as the first stressor in the CVS group to observe acute effects of inhibiting PV INs on passive coping behavior. Mice were suspended $55 \mathrm{~cm}$ above ground using a $17 \mathrm{~cm}$ long tape that was attached to a suspension bar, for a total time period of $6 \mathrm{~min}$. Sessions were video recorded from the side to allow full body visualization of mice behaviors-active coping (struggling) behavior, which comprised of strong shaking of the body and movement of all four limbs, and passive coping (immobility) behavior which comprised of not making any active limb movements. Latency to reach immobility was also measured. Behaviors were quantified by an experimenter blinded to the group assignments using behavioral scoring software Kinoscope 3.0.4. Behaviors during the 6-min block were reported. 
A

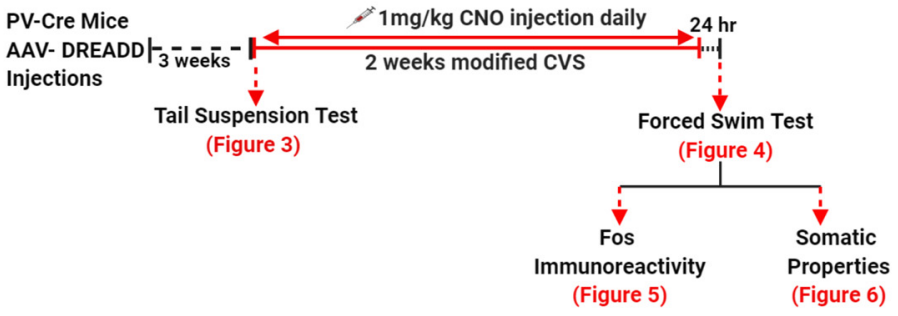

B
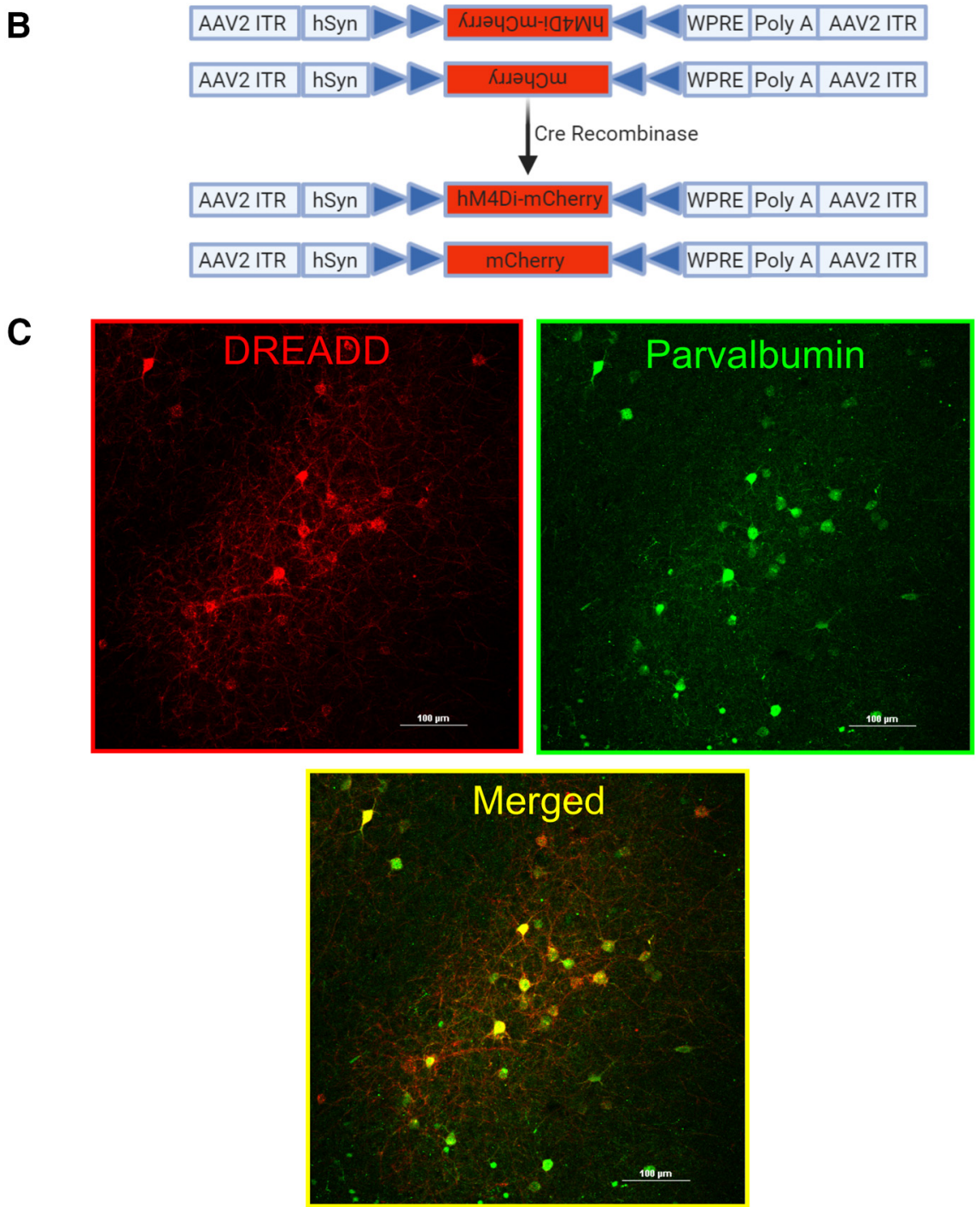

Figure 1. Experimental design and targeting of PV INs in the PFC using DREADDs. A, Experimental design and timeline. C57BL/6J PV-Cre mice $\sim 7.5$ months of age underwent surgery to inject AAV2-hM4Di-mCherry (inhibitory DREADD) or AAV2-mCherry (control virus). Mice were allowed three weeks to recover to enable sufficient time for DREADD expression. Animals were then subjected to CVS procedure twice a day for $14 \mathrm{~d}$ or served as controls. The first stressor was a TST to determine acute effects of PV IN inhibition in animals within the CVS group. Animals were dosed with $1 \mathrm{mg} / \mathrm{kg}$ CNO before each stressor to inhibit PV INs during the CVS procedure; $24 \mathrm{~h}$ after the end of CVS, animals were subjected to FST, following which mice were euthanized, body was perfused, and brains and organs were collected. No CNO was administered during the testing phase in FST. B, Design of AAV2-hSyn-hM4DimCherry (top) and AAV2-hSyn-mCherry (bottom) vectors employing the DIO strategy. Two pairs of heterotypic, antiparallel loxP recombination sites (blue triangles) achieve Cre-mediated transgenes inversion and expression under the control of hSyn promoter. ITR, left-inverted terminal repeat; hSyn, human synapsin; WPRE, woodchuck hepatitis DREADD posttranscriptional regulatory element. $\boldsymbol{C}$, Successful Cre-mediated recombination of DREADDs demonstrated by presence of red mCherry (left); green fluorescence identifies PV INs (right); hM4Di receptors selectively expressed in PV INs as illustrated by mCherry (red) and PV (green) co-expression (merged, yellow, bottom middle image). Scale bar: $100 \mu \mathrm{m}$. 


\section{FST}

FST was conducted $24 \mathrm{~h}$ following completion of the CVS procedure. Mice were placed in a clear cylinder (2-I glass beaker) filled with water $\left(24 \pm 1^{\circ} \mathrm{C}, 18-\mathrm{cm}\right.$ depth) for a period of $10 \mathrm{~min}$. Sessions were video recorded from the side to allow full body visualization for total immobility duration, which comprised of not making any active movements or floating in the water without struggling, and total swimming duration, which comprised of moving limbs in an active manner and making circular movements around the cylinder. Behaviors were quantified by an experimenter blinded to the group assignments using behavioral scoring software Kinoscope 3.0.4. Behaviors during the 10-min block were reported. It should be noted that all mice in the study (including CVS and controls) underwent FST as a behavioral test. This includes the mice that had TST in the beginning of the CVS paradigm. To control for a potential effect of chronic exposure to CNO, a separate group of PV-Cre mice were chronically injected with either saline or $\mathrm{CNO}$ for $14 \mathrm{~d}$ during CVS $(2 \times 2$ design $)$ and then behaviorally tested in the FST.

\section{Euthanasia and tissue collection}

Mice were euthanized with an overdose of sodium pentobarbital after FST, and transcardially perfused with $0.9 \%$ saline followed by $4 \%$ paraformaldehyde in $0.01 \mathrm{M}$ PBS, $\mathrm{pH}$ 7.4. Brains were removed and postfixed in $4 \%$ paraformaldehyde at $4^{\circ} \mathrm{C}$ for $24 \mathrm{~h}$, then transferred to $30 \%$ sucrose in $0.01 \mathrm{~m} \mathrm{PBS}$ at $4^{\circ} \mathrm{C}$ until processed. Thymi and adrenal glands were collected, cleaned, and weighed from all animals.

\section{Immunohistochemistry}

Brains were sectioned into $30-\mu \mathrm{m}$ coronal sections using a freezing microtome $\left(-20^{\circ} \mathrm{C}\right)$. Sections were collected into 12 wells (1/12) containing cryoprotectant solution [30\% sucrose, $1 \%$ polyvinyl-pyrolidone (PVP-40), and $30 \%$ ethylene glycol, in 0.01 M PBS]. Immunohistochemistry was performed at room temperature (RT) and $0.01 \mathrm{~m}$ PBS was used to rinse brain slices before each treatment described below.

\section{$P V$ and DREADD co-localization}

Targeting of IL mPFC PV neurons and recombination of hM4Di DREADD was verified by co-localization of PV immunoreactivity with virally expressed mCherry fluorescence. Free floating sections were incubated in blocking solution $[4 \%$ normal goat serum (NGS), $0.1 \%$ Triton $X-$ $100,0.1 \%$ bovine serum albumin (BSA) in $0.01 \mathrm{~m}$ PBS] for $1 \mathrm{~h}$ at RT. After that, sections were incubated with rabbit anti-PV (1:1000, Abcam, ab11427) overnight, followed by visualization with donkey- anti-rabbit Alexa Fluor 488 conjugate (1:500, Invitrogen, A11034). Images were acquired using Nikon Confocal Microscope at $40 \times$ magnification.

\section{Injection site and viral spread}

To determine whether virus spread was restricted to the IL, sections were incubated with a rabbit anti-mCherry (1:500, Abcam, ab167453) for $2 \mathrm{~h}$, followed by visualization with goat anti-rabbit Cy5 conjugate (1:500, Invitrogen, A10523). Images were acquired using Carl Zeiss Imager Z1 at $2.5 \times$ and $5 \times$ magnification. Viral spread was mapped onto its respective focal plane and bregma level by outlining the spread of the infection from confocal images onto corresponding brain atlas illustrations (Lein et al., 2007). Fluorescent cells were counted using semi-automated analysis macro in the ImageJ software package (National Institutes of Health). The threshold was adjusted to detect the fluorescence and cells counted using the Analyze Particle feature. The percentage of infected cells in IL was calculated by dividing the number of mCherry-positive cells in IL by the total number of mCherry-positive cells in a specific focal plane. Brain bregma coordinates used for IL cytoarchitecture were defined in the Franklin and Paxinos mouse brain atlas (third edition; Franklin and Paxinos, 2007).

Fos immunoreactivity. Neuronal activation was measured using Fos as a marker. Free floating sections were incubated in $1 \%$ sodium borohydride for $20 \mathrm{~min}$ and then in $3 \%$ hydrogen peroxide in PBS for 20 min. After that, slices were incubated in blocking solution (NGS, $0.3 \%$ Triton X-100, 0.2\% BSA in $0.01 \mathrm{~m}$ PBS) for $1 \mathrm{~h}$. Sections were then incubated with Fos rabbit polyclonal antibody (1:200, Santa Cruz, sc-52) in blocking solution overnight and was followed by incubation in secondary antibody (biotinylated goat anti-rabbit, (1:400; Vector Laboratories, BA1000) in blocking solution for $1 \mathrm{~h}$ the next day. Sections were then treated with avidin-biotin horseradish peroxidase complex (1:800 in $0.01 \mathrm{M}$ PBS; Vector Laboratories, PK6100) for $1 \mathrm{~h}$ and then developed with an 8-min incubation in 3,3'-diaminobenzidine (DAB)-Nickel solution: $10 \mathrm{mg}$ DAB tablet (Sigma, DF905), $0.5 \mathrm{ml}$ of a $2 \%$ aqueous nickel sulfate solution, $20 \mu \mathrm{l}$ of $30 \%$ hydrogen peroxide in $50 \mathrm{ml}$ of $0.01 \mathrm{M}$ PBS. Sections were mounted on superfrost slides (Fisherbrand, Fisher), allowed to dry, dehydrated with xylene, and then coverslipped with DPX mounting medium (Sigma).

Images were acquired using microscope Carl Zeiss Imager Z1 at a $5 \times$ objective. For analysis, we counted minimum of three bilateral sections per brain region/animal covering the prelimbic cortex (PrL; bregma 2.80-1.98 $\mathrm{mm}$ ), basolateral amygdala (BLA; bregma -1.06 to -1.58 ), and ventrolateral periaqueductal gray (vIPAG; bregma -4.16 to -4.36 ) as defined in the Franklin and Paxinos mouse brain atlas (Franklin and Paxinos, 2007). The number of Fos-positive nuclei was counted using a semi-automated analysis macro in the ImageJ software package (National Institutes of Health). The macro was generated using the Analyze Particle tool, with a defined common level of background intensity, nuclei circularity and size (previously validated manually). The relative density of the population of immunopositive cells was calculated by dividing the number of Fos-positive cells by the respective brain area.

\section{Statistical analysis}

The experiment was setup as a $2 \times 2$ study design, with stress (CVS or No CVS) and DREADD (hM4Di or control) as factors with a sample size of $n=10$ per group (for experimental design and timeline, see Fig. 1A). Statistical analyses for FST and Fos protein quantification were performed using a two-way ANOVA with stress (No CVS, 
Table 1: Data structure, type of test to analyze the data, and observed power of key results

\begin{tabular}{|c|c|c|c|}
\hline & Data structure & Type of test & Power \\
\hline $\bar{a}$ & Normal distribution & $\begin{array}{l}\text { Unpaired sample } \\
t \text { test (struggling) }\end{array}$ & $\begin{array}{l}\text { Main effect hM4Di DREADD : } \\
\text { Cohen's } d=1.2\end{array}$ \\
\hline b & Normal distribution & $\begin{array}{l}\text { Unpaired sample } \\
t \text { test (immobility) }\end{array}$ & $\begin{array}{l}\text { Main effect hM4Di DREADD: } \\
\text { Cohen's } d=1.3\end{array}$ \\
\hline c & Normal distribution & $\begin{array}{l}\text { Unpaired sample } \\
t \text { test (latency to immobility) }\end{array}$ & $\begin{array}{l}\text { Main effect hM4Di DREADD: } \\
\text { Cohen's } d=1.3\end{array}$ \\
\hline d & Normal distribution & $\begin{array}{l}\text { Two-way ANOVA } \\
\text { (swimming duration) }\end{array}$ & $\begin{array}{l}\text { Main effect of stress: } 0.91 \\
\text { Main effect of hM4Di DREADD: } 0.55\end{array}$ \\
\hline$f$ & Normal distribution & $\begin{array}{l}\text { Two-way ANOVA } \\
\text { (immobility duration) }\end{array}$ & $\begin{array}{l}\text { Main effect stress: } \\
\quad \text { Power }=0.85\end{array}$ \\
\hline h & Normal distribution & $\begin{array}{l}\text { Two-way ANOVA } \\
\quad(\mathrm{PrL})\end{array}$ & $\begin{array}{l}\text { Main effect stress: } \\
\text { Power }=0.98 \\
\text { Interaction (stress } \times \text { hM4Di DREADD) } \\
\text { Power }=0.76\end{array}$ \\
\hline i & Normal distribution & $\begin{array}{l}\text { Two-way ANOVA } \\
\text { (IL) }\end{array}$ & $\begin{array}{l}\text { Main effect stress: } \\
\quad \text { Power }=0.99\end{array}$ \\
\hline j & Normal distribution & $\begin{array}{l}\text { Two-way ANOVA } \\
\text { (BLA) }\end{array}$ & $\begin{array}{l}\text { Main effect stress: } \\
\quad \text { Power }=0.89\end{array}$ \\
\hline $\mathrm{k}$ & Normal distribution & $\begin{array}{l}\text { Two-way ANOVA } \\
\text { (vIPAG) }\end{array}$ & $\begin{array}{l}\text { Main effect stress: } \\
\quad \text { Power }=0.94\end{array}$ \\
\hline I & Normal distribution & $\begin{array}{l}\text { Two-way ANOVA } \\
\text { (adrenal weight) }\end{array}$ & $\begin{array}{l}\text { Main effect stress: } \\
\text { Power }=0.90 \\
\text { Interaction (stress } \times \text { hM4Di DREADD) } \\
\text { Power }=0.57\end{array}$ \\
\hline$p$ & Normal distribution & $\begin{array}{l}\text { Unpaired sample } \\
t \text { test (viral spread in IL) }\end{array}$ & $\begin{array}{l}\text { Main effect hM4Di DREADD in IL: } \\
\text { Cohen's } d=1.2\end{array}$ \\
\hline
\end{tabular}

Table depicts the data structure, type of statistical test used, and power of key results for each of the statistical tests used in the manuscript. Each analysis includes a letter indicator linking the test in the table to the analysis in the text.

CVS) and DREADD (Control, hM4Di) as main factors. TST data were analyzed using Student's $t$ test. FST measurements over time were done using two-way repeated measure ANOVA with stress (No CVS, CVS) and DREADD (Control, hM4Di) as main factors analyzed over time. Tukey's post hoc test was performed in cases with significant interaction between factors. Because specific hypotheses were formed a priori on the effects of CVS within groups, planned comparisons using Fisher's least significant difference (LSD) were performed in cases with no significant interaction effect. Data were analyzed by STATISTICA 7.0 (Statsoft) and GraphPad Prism 8.1.2 (GraphPad Software). Outliers were detected using the Grubbs' test (GraphPad Software) and removed from analysis. After exclusion of outliers, data were assessed for normal distribution (Shapiro-Wilk) and appropriate parametric and/or non-parametric tests used. Data are presented as mean \pm SEM with statistical significance set at $p \leq 0.05$. See Table 1 for details regarding data structure and type of test used. Superscript letters listed with $p$ values correspond to the statistical tests shown in Table 1.

\section{Results}

\section{Selective targeting of PV INs achieved using DREADDs}

The AAV constructs used in this experiment are shown in Figure 1B. Following Cre recombination, the viral 
construct expresses inhibitory DREADD sequence hM4Di along with a fluorescent reporter (mCherry), allowing visualization of cells undergoing recombination. Control virus was a Cre-inducible mCherry lacking the DREADD hM4Di construct. Cre-mediated recombination of hM4Di-mCherry and cell type specificity were conferred by immunostaining. Expression of red hM4Di-mCherry demonstrates successful recombination (Fig. 1C, left). hM4Di-mCherry expression was restricted to PV INs only (Fig. 1C, right), confirmed by colocalization of red mCherry with green (Alexa Fluor 488) PV immunostaining, resulting in yellow cells in the merged image (Fig. $1 C$, bottom).

\section{Targeting of IL and viral spread}

Figure $2 A$ depicts viral injection site and spread of virus determined by the presence of mCherry and far-red (Cy5) fluorescence in animals injected with hM4Di DREADD $(n=9)$. It shows the stereotaxic injection sites and that AAV DREADD expression was primarily restricted to the IL, with some minor spread into the PrL and dorsal peduncular (DP) cortex located above and below IL, respectively. Injection sites and viral spread were located primarily within the bregma range 1.78-1.54 (Franklin and Paxinos, 2007). Figure $2 B$ is a representative image from an animal demonstrating red mCherry fluorescence primarily in the IL delineated by white dashed lines. Quantification of percentage of transfected neurons from animals injected with hM4Di DREADD, revealed expression was significantly contained, with $\sim 72 \%$ of transfected cells localized in the IL $\left(t=4.6, \mathrm{df}=16, p=0.0003^{\text {p }}\right.$; Fig. $\left.2 C\right)$.

\section{Acute inhibition of PV INs: TST}

The behavioral consequences of acute inhibition of PV INs in the IL were tested by using the TST as the first stressor in the CVS paradigm (Fig. 3). Animals were dosed with $1 \mathrm{mg} / \mathrm{kg}$ CNO $30 \mathrm{~min}$ before the start of TST. We observed significant changes in coping behavior following acute inhibition of PV INs in the IL. Compared with control mice, mice expressing hM4Di showed significant reduction in struggling duration $(t=2.7, \mathrm{df}=18$, $p=0.02^{\text {a }}$; Fig. $3 A$ ), significant increase in immobility duration $\left(t=2.9, \mathrm{df}=18, p=0.009^{\mathrm{b}}\right.$; Fig. $\left.3 B\right)$ and decreased latency to immobility $\left(t=2.5, \mathrm{df}=17, p=0.02^{\mathrm{C}}\right.$; Fig. $\left.3 C\right)$, respectively.

\section{Injection site and spread of hM4Di} in PFC of PV-Cre Mice

\section{Bilateral Injection of hM4Di into the} IL of PV-Cre Mice

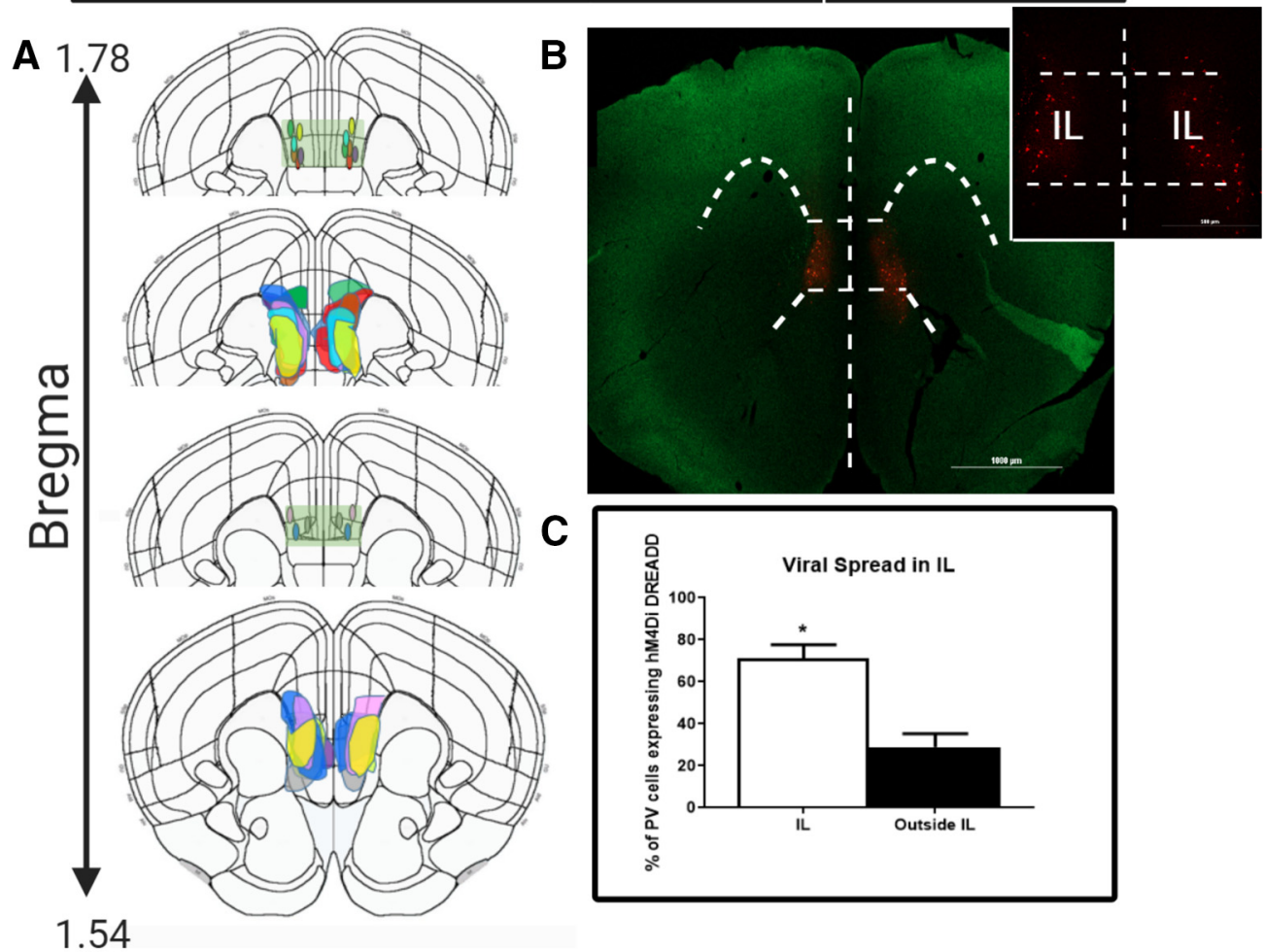

Figure 2. Injection site, viral spread. and targeting of IL. $\boldsymbol{A}$, Injection site and viral spread mapped onto respective mouse bregma coordinates, following bilateral injection of hM4Di DREADD into the IL of PV-Cre mice $(n=9)$. Light green rectangular box depicts the IL region with the injection sites restricted to the region. Each animal's injection site and viral spread has been represented by a unique color. $\boldsymbol{B}$, Representative image from one animal demonstrating the viral spread in PFC detected by red mCherry fluorescence. Image shows the spread was restricted to the IL with the white dashed lines outlining the IL cortex region of the PFC. Scale bars: 1000 and $500 \mu \mathrm{m}$. C, Percentage of DREADD transfected PV INs in the IL of PV-Cre mice. The percentage of infected cells in IL was calculated by dividing the number of mCherry-positive cells in IL by the total number of mCherry-positive cells in a specific focal plane and bregma coordinate. Brain bregma coordinates used for IL cytoarchitecture were taken from Franklin and Paxinos (2007). *indicates significant effect $p<0.05$ compared to outside IL group. Values represent mean \pm SEM, $n=9$ per group. 


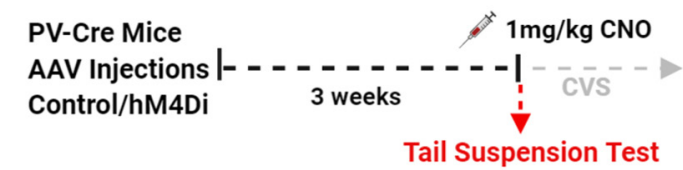

A Total Struggling Duration

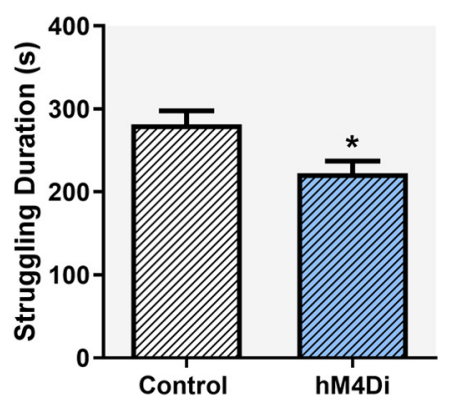

B Total Immobility Duration

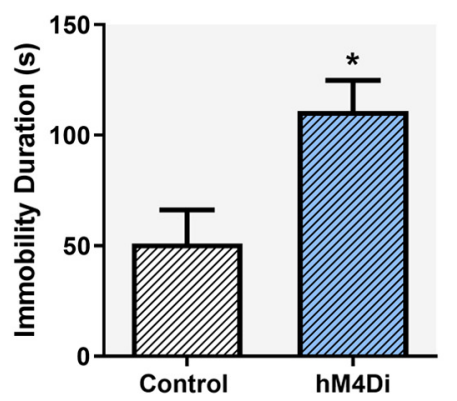

C Latency to Immobility

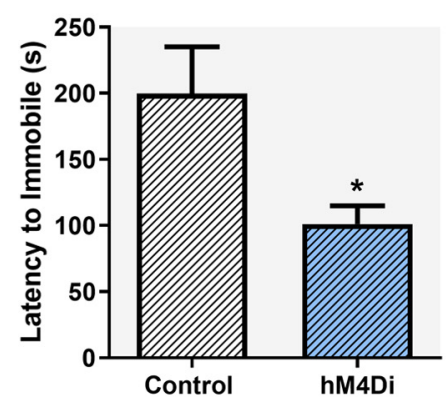

Figure 3. Impact of acute chemogenetic inhibition of PV IN in the IL mPFC on coping behavior in the TST. Acute inhibition of PV INs in the IL mPFC during TST, reduced total time spent struggling $(\boldsymbol{A})$, increased total time spent immobile $(\boldsymbol{B})$, and reduced latency to immobility $(\boldsymbol{C})$. All mice were treated with CNO $(1 \mathrm{mg} / \mathrm{kg}$, i.p.) $30 \mathrm{~min}$ before TST. Behaviors were analyzed for a total time of $6 \mathrm{~min}$. Values represent mean \pm SEM, $n=9-10$ per group; $*$ indicates significant effect $p<0.05$ versus corresponding control group.

\section{Chronic inhibition of PV INs during CVS: Impact on FST}

Animals were tested for coping behaviors in the FST 24 $\mathrm{h}$ after cessation of CVS. Our purpose was to test whether inhibition of PV INs during the chronic stress regimen could block the aggregate effect of repeated stress on subsequent coping behavior (FST used as a novel stressor), brain activation patterns (Fos expression) and somatic endpoints (organ and body weights). All subjects received viral (Control or $\mathrm{hM} 4 \mathrm{Di}$ ) and CNO treatments, and because CNO was only administered during CVS, any phenotypes observed during FST were interpreted as reflecting an impact of PV IN manipulation during CVS on subsequent stress coping behavior. We observed significant differences in FST coping behaviors following chronic inhibition of PV INs during CVS. Specifically, chronic PV IN inhibition during stress increased active coping (swimming) and reduced passive coping (immobility) behaviors in the FST. Two-way ANOVA of total swimming duration showed a significant main effect of stress $\left(F_{(1,35)}=11.7 ; p=0.002^{\text {d; }}\right.$ Fig. $\left.4 A\right)$ and DREADD $\left(F_{(1,35)}=\right.$ $\left.4.7 ; p=0.037^{d}\right)$ but no stress $\times$ DREADD interaction $\left(F_{(1,35)}=1.47 ; p=0.2\right)$. Planned comparisons revealed a significant increase in swimming duration in the CVS hM4Di group compared with both CVS Control $(p=0.02$; Fig. $4 A$ ) and No CVS hM4Di group ( $p=0.002$; Fig. $4 A$ ). Analysis of swimming behavior over time showed a main effect of stress $\left(F_{(1,35)}=11.7 ; p=0.002^{\mathrm{e}}\right.$; Fig. $\left.4 B\right)$, $\operatorname{DREADD}\left(F_{(1,35)}=4.7 ; p=0.037^{\mathrm{e}}\right)$ and time $\left(F_{(9,315)}=68.2\right.$; $p<0.0001^{\mathrm{e}}$ ) but no interaction effects were observed among the three groups time $\times$ stress $\times \operatorname{DREADD}\left(F_{(9,315)}=\right.$ $0.6 ; p=0.78$ ). Planned comparisons revealed significant increase in swimming duration in the CVS hM4Di group at 2-, 3-, 4-, and 8-min time points compared with No CVS hM4Di group $(p=0.004, p=0.009, p=0.01$, and $p=$ 0.009 , respectively; Fig. $4 B$ ).

Two-way ANOVA of total immobility duration showed a significant main effect of stress $\left(F_{(1,35)}=9.5 ; p=0.004^{\dagger}\right.$; Fig. $4 C)$, no main effect of DREADD $\left(F_{(1,35)}=1.7 ; p=0.2\right)$ and no stress $\times$ DREADD interaction $\left(F_{(1,35)}=3.9\right.$; $p=0.057$ ). Planned comparisons revealed a significant reduction in immobility duration in the CVS hM4Di group compared with CVS Control $(p=0.02)$ and No CVS hM4Di group $(p=0.0009)$. There was a significant main effect of stress $\left(F_{(1,35)}=9.5 ; p=0.004\right.$; Fig. $\left.4 C\right)$ and time $\left(F_{(9,315)}=\right.$ 

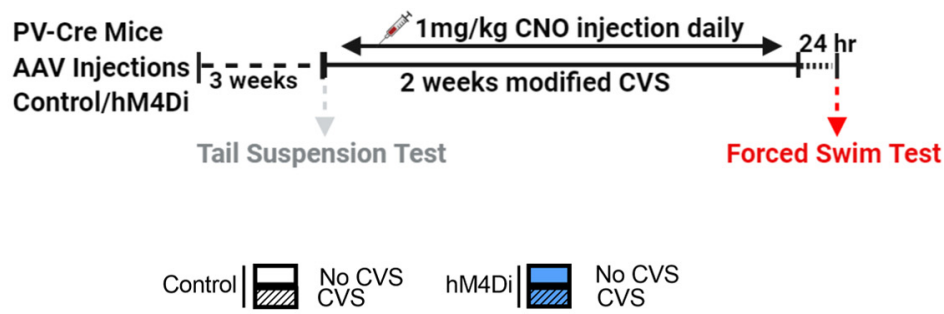

\section{A Total Swimming Duration B Swimming Over Time}

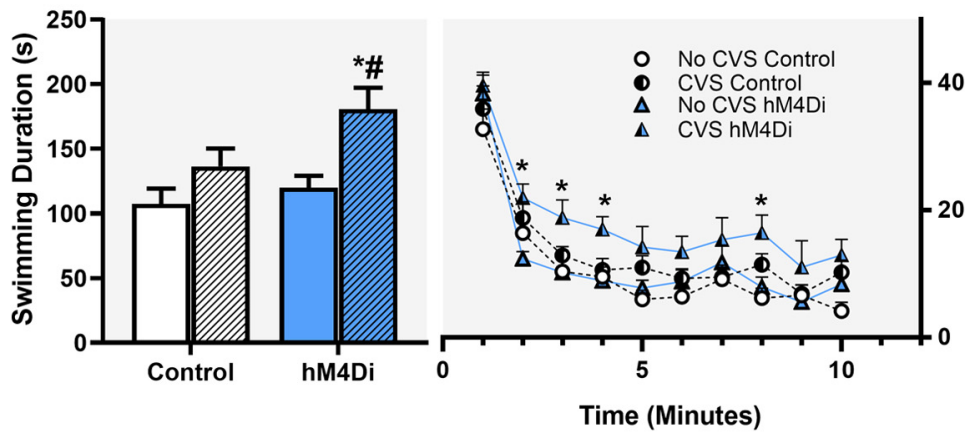

C Total Immobility Duration D Immobility Over Time

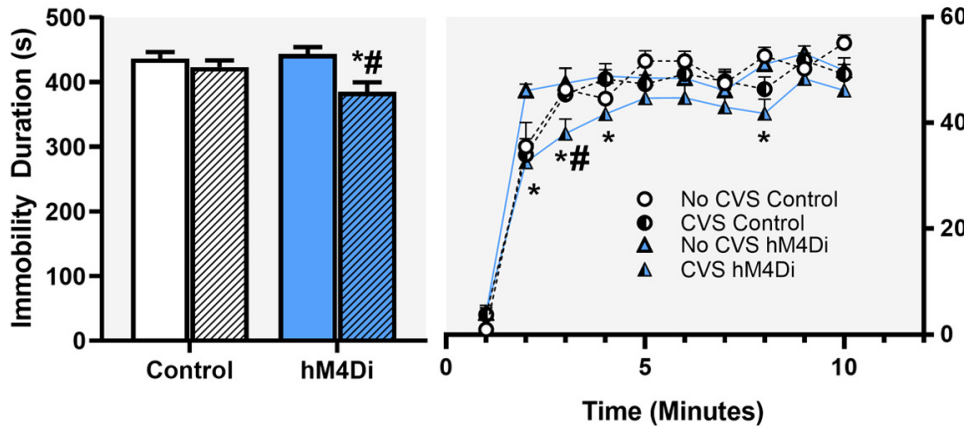

Figure 4. Effects of chronic chemogenetic inhibition of PV INs during CVS on coping behavior in the FST following CVS. Chronic inhibition of PV INs in the IL mPFC during CVS, resulted in increased total time spent swimming $(\boldsymbol{A})$ and decreased total time spent immobile $(\boldsymbol{C})$ in the FST. $\boldsymbol{B}, \boldsymbol{D}$, Changes in swimming and immobility behavior, respectively, over the $10 \mathrm{~min}$ of FST. Values represent mean \pm SEM, $n=9-$ 10 per group; * indicates planned comparison significant effect $p<0.05$ versus corresponding No CVS hM4Di group; \# indicates planned comparison significant effect $p<0.05$ versus corresponding CVS Control group. Extended Data Figure 4-1 demonstrates chronic inhibition of PV INs did not affect locomotor activity. Extended Data Figure 4-2 demonstrates chronic CNO administration did not lead to any changes in FST behavior following CVS or control. Extended Data Figure 4-3 demonstrates CVS effects on FST did not depend on the age of the animal and also shows chronic injection stress and housing conditions had no effect on FST behavior in control animals.

$156.4 ; p<0.0001^{9}$ ) on immobility duration but no interaction effects were observed among the three groups time $\times$ stress $\times \operatorname{DREADD}\left(F_{(9,315)}=1.1 ; p=0.4\right)$. Planned comparisons revealed a significant decrease in immobility in the CVS hM4Di group at 2-, 3-, 4-, and 8-min time points compared with No CVS hM4Di group $(p=0.00009, p=0.005$, $p=0.04$, and $p=0.007$, respectively; Fig. $4 D$ ) and at the 3min time point compared with the CVS Control group $(p=0.03$; Fig. $4 D)$.

Chronic PV IN inhibition had no effect on locomotor activity, demonstrated by no significant difference in total distance traveled $(t=0.74 ; \mathrm{df}=18 ; p=0.46$; Extended Data Fig. $4-1 A)$ or velocity $(t=0.75 ; \mathrm{df}=18 ; p=0.47$; Extended Data Fig. 4-1B) demonstrating behavioral effects were not confounded by locomotor deficits. Control experiments performed on a separate group of animals to determine effects of chronic CNO in FST behavior showed no significant difference in immobility or swimming duration. Two-way ANOVA of total immobility duration did not show a significant main effect of stress $\left(F_{(1,28)}=0.81\right.$; $p=0.38$; Extended Data Fig. 4-2A) no main effect of DREADD $\left(F_{(1,2)}=0.07 ; p=0.8\right)$ and no stress $\times$ DREADD interaction $\left(F_{(1,28)}=0.13 ; p=0.72\right)$. Two-way ANOVA of total swimming duration did not show a significant main effect of stress $\left(F_{(1,28)}=0.86 ; p=0.36\right.$; Fig. $\left.4-2 B\right)$, no main effect of DREADD $\left(F_{(1,28)}=0.16 ; p=0.69\right)$, and no stress $\times$ DREADD interaction $\left(F_{(1,28)}=0.11 ; p=0.74\right)$.

\section{Chronic inhibition of PV INs during CVS: Impact on Fos induction by FST}

To test for Fos activation, animals were perfused after FST and brains were collected to analyze neuronal 
activation in brain regions typically activated by stress. We observed significant reduction in Fos induction in the CVS Control group compared with No CVS Control group, in the PrL, IL, BLA, and vIPAG. Inhibition of PV INs during CVS attenuated the reduction in Fos expression caused by CVS in the PrL, BLA, and VIPAG but not in the IL. Analysis of the PrL revealed a significant main effect of stress $\left(F_{(1,30)}=17.5 ; p=0.0002 \mathrm{~h} ;\right.$ Fig. $\left.5 A\right)$ and a significant stress $\times$ DREADD interaction $\left(F_{(1,30)}=7.7 ; p=0.009^{\mathrm{h}}\right)$. Post hoc analysis using Tukey's test revealed a significant reduction in Fos expression in the CVS Control group $(p=0.0003)$, which was attenuated by chronic PV IN inhibition in the CVS hM4Di group $(p=0.75)$. There was a significant main effect of stress only $\left(F_{(1,27)}=21.2 ; p<0.0001^{i}\right.$; Fig. $5 B$ ) on Fos expression in the IL. There was a significant main effect of stress in the BLA $\left(F_{(1,20)}=12.4 ; p=0.004\right.$; Fig. $5 C)$ and vIPAG $\left(F_{(1,17)}=20.5 ; p<0.0001^{\text {k }}\right.$; Fig. $\left.5 D\right)$ as well, with planned comparisons revealing significant reduction in Fos expression in the CVS Control group $(p=0.008$ and $p=0.0009$ in BLA and VIPAG, respectively) that was attenuated by chronic PV IN inhibition in the CVS hM4Di group $(p=0.75$ and $p=0.08$ in BLA and vIPAG, respectively). Analysis of Fos protein expression in the lateral septum (LS), anterior and ventral bed nucleus of the stria terminalis (BNST) and dorsolateral PAG (dIPAG) showed no significant treatment effects of PV IN inhibition, demonstrating those regions were not affected by PV IN modulation (Extended Data Fig. 5-1).

\section{Chronic inhibition of PV INs during CVS: impact on somatic measurements}

Organs and body weights were used to assess somatic effects of CVS. Adrenal gland hypertrophy and/or thymic
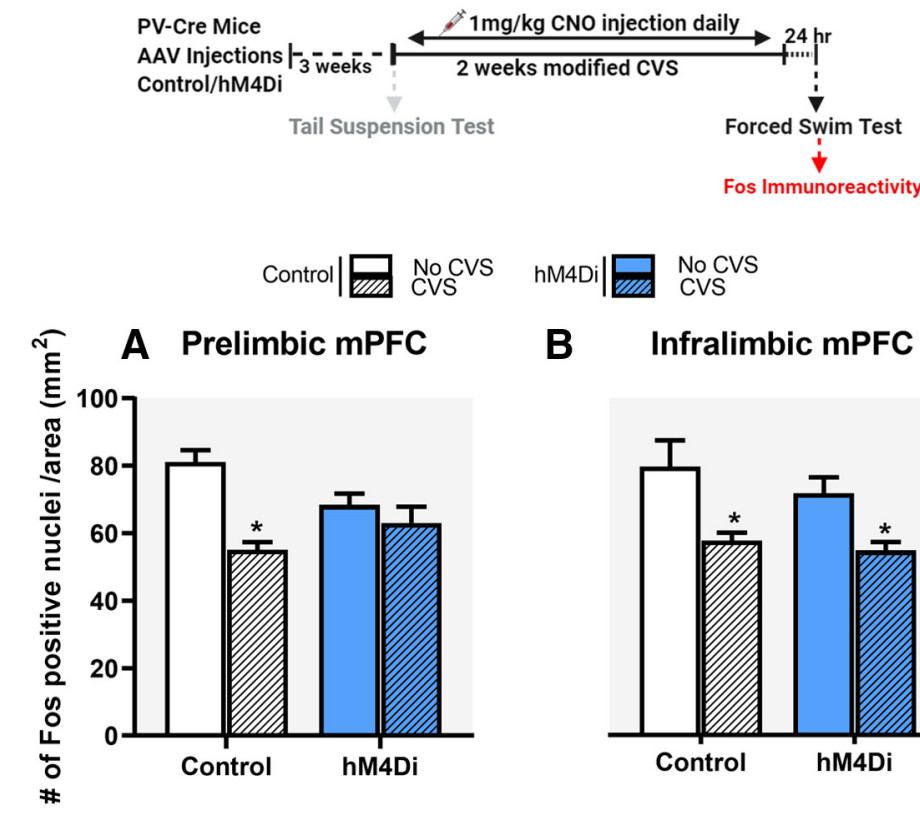

hM4Di| $\begin{aligned} & \text { No CVS } \\ & \text { CVS }\end{aligned}$

B Infralimbic mPFC
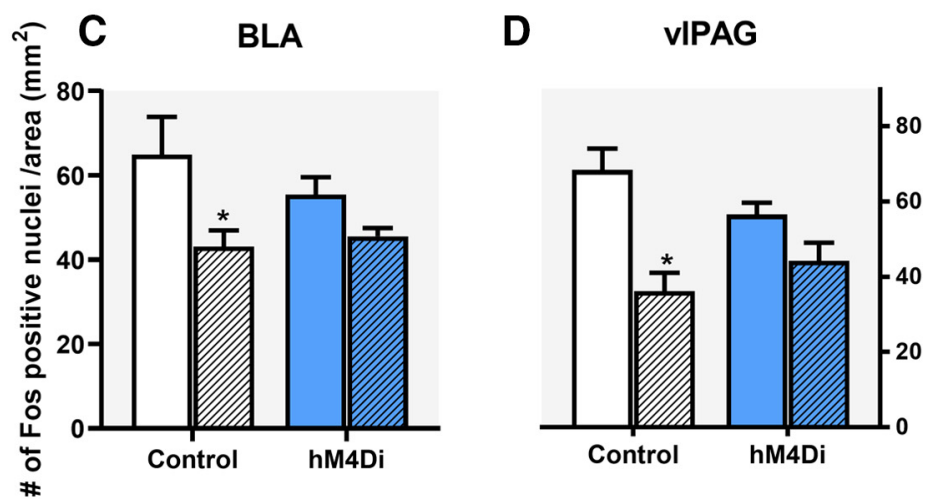

Figure 5. Fos immunoreactivity in the PrL, IL, BLA, and vIPAG. Chronic inhibition of PV INs in the IL mPFC during CVS, attenuated CVSmediated reduction in Fos expression in the PrL, BLA, and vIPAG, respectively $(\boldsymbol{A}, \boldsymbol{C}, \boldsymbol{D})$ but did not prevent CVS-mediated reduction in Fos expression in the IL cortex $(\boldsymbol{B})$ following FST. Values are presented as mean \pm SEM; $n=7-10$ per group; * indicates significant result $p<0.05$ post hoc $(\boldsymbol{A})$ and planned comparisons $(\boldsymbol{C}, \boldsymbol{D})$ compared with respective No CVS Control groups. PrL, IL, BLA, and vIPAG stands for prelimbic, infralimbic, basolateral amygdala and ventrolateral periaqueductal grey, respectively. Extended Data Figure 5-1 demonstrates Fos expression in various other brain regions where no significant effect of PV IN modulation was observed. 
atrophy are often observed following chronic stress and are used as indicators of repeated/chronic hypothalamic pituitary adrenal (HPA) axis activation. In our experiments, there was a main effect of stress $\left(F_{(1,35)}=11.2 ; p=0.002\right.$; Fig. $6 A)$ and a significant stress $\times$ DREADD interaction $\left(F_{(1,35)}=4.8 ; p=0.035^{\prime}\right)$ on adrenal weights. Post hoc analysis using Tukey's test revealed that CVS Control group had significantly increased adrenal weight compared with No CVS Control group $(p=0.002)$, which was attenuated by CVS hM4Di when compared with No CVS hM4Di group $(p=0.84)$. There was a main effect of stress on thymus weight $\left(F_{(1.35)}=161.4 ; p<0.0001^{\mathrm{m}} ;\right.$ Fig. $\left.6 B\right)$, with no effect of DREADD $\left(F_{(1,35)}=0.2 ; p=0.7\right)$ or stress $\times$ DREADD interaction $\left(F_{(1,35)}=57 ; p=0.1\right)$.

Decreased body weight gain is observed following chronic mild stress exposure in rodents (Ghosal et al., 2017). We observed a significant main effect of stress on final body weight $\left(F_{(1,35)}=6.6 ; p=0.01^{\mathrm{n}} ;\right.$ Fig. $\left.6 C\right)$ with no effect of DREADD $\left(F_{(1,35)}=0.2 ; p=0.6\right)$ or stress $\times$ DREADD interaction $\left(F_{(1.35)}=0.006 ; p=0.9\right)$, consistent with known effects of CVS on body weight gain. Planned comparisons revealed final body weight in CVS group to be significantly lower than No CVS Control group $(p=0.03)$, which was attenuated by CVS hM4Di when compared with No CVS hM4Di group ( $p=0.08$; Fig. $6 C$ ). Two-way repeated measures ANOVA of body weight over time during the $14 \mathrm{~d}$ CVS paradigm showed a main effect of stress $\left(F_{(1,35)}=5.3\right.$, $\left.p=0.03^{\circ}\right)$ and time $\left(F_{(3,108)}=4.5 ; p=0.005^{\circ}\right.$; Fig. $\left.6 D\right)$. Planned comparisons revealed body weight in CVS Control group to be significantly lower than No CVS Control only on day $14(p=0.03$; Fig. $6 D)$. Control experiments to determine effects of chronic CNO on body weight showed no significant difference. Two-way ANOVA of total body weight showed a significant main effect of stress $\left(F_{(1,28)}=18.6\right.$; $p=0.002$; Fig. 4-2C), no main effect of treatment $\left(F_{(1,28)}=\right.$ $0.41 ; p=0.52)$ and no stress $\times$ treatment interaction $\left(F_{(1,28)}=\right.$
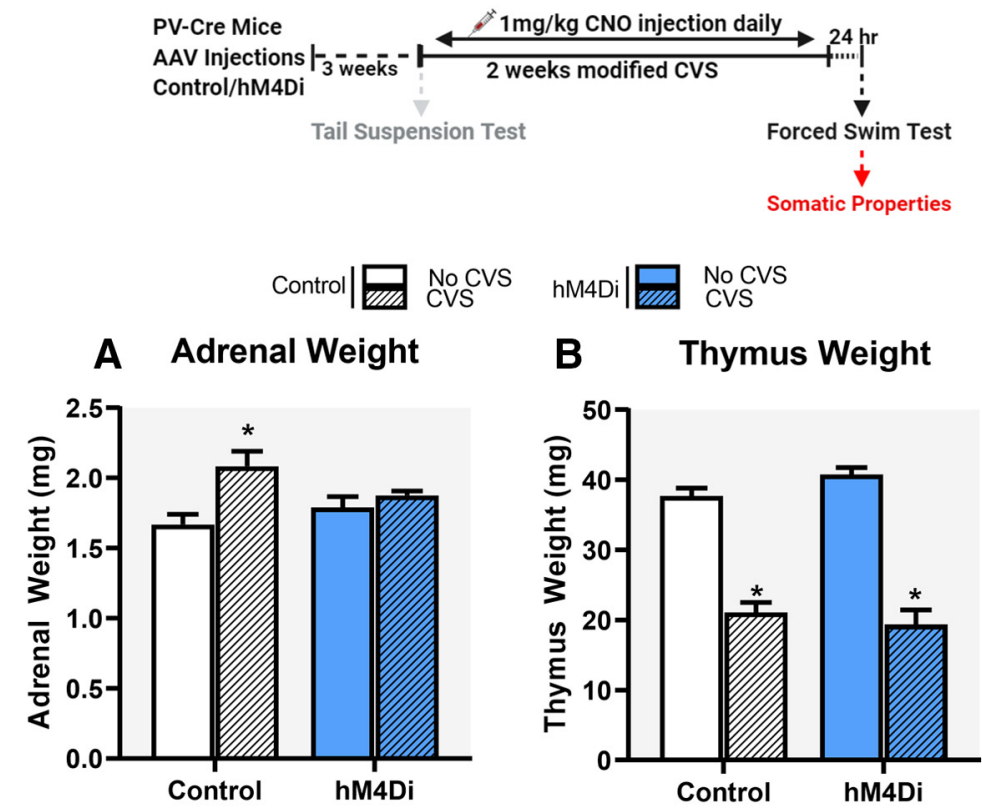

\section{Final Body Weight}

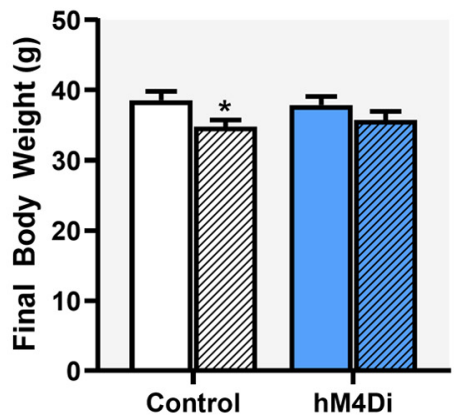

\section{Body Weight Over Time}

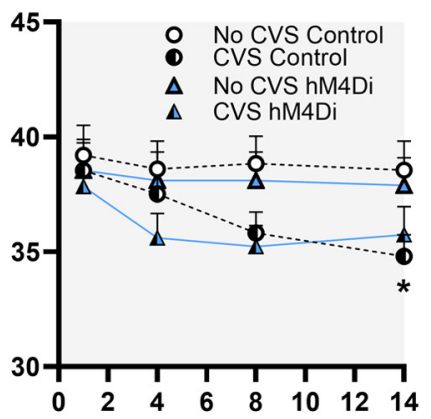

Figure 6. Impact of chronic stress on organ and body weights. Chronic inhibition of PV INs in the IL mPFC during CVS, attenuated CVS mediated increases in adrenal gland weight $(\boldsymbol{A})$ and attenuated CVS mediated decreases in body weight $(\boldsymbol{C}, \boldsymbol{D})$. No change in CVS-induced decreases in thymus weight was observed following PV IN inhibition (B). Data are presented as absolute organ and body weights. Values represent mean \pm SEM; $n=9-10$ per group; $*$ indicates planned comparisons significant effect $p<0.05$ versus corresponding No CVS Control groups. 
$0.21 ; p=0.65$ ). Planned comparisons revealed body weight in both Saline and CNO CVS groups to be significantly lower than respective No CVS controls $(p=0.04$ and $p=$ 0.01; Fig. 6D)

\section{Discussion}

Our studies support a role for IL GABAergic PV INs in stress-mediated behavioral and somatic phenotypes. Using inhibitory DREADDs to inhibit the activity of PV INs during a modified CVS paradigm, we have established a causal role of IL PV INs in initiating and coordinating coping strategies and somatic outcomes in response to stress. Inhibition of PV IN during the CVS resulted in an increase in active coping strategy during FST, suggestive of dynamic behavioral remodeling during an aversive challenge. Chronic stress-induced behavioral alterations were accompanied by changes in neuronal activation patterns quantified by Fos expression following FST. Chronic PV IN inhibition attenuated CVS-induced reductions in Fos expression in PrL, BLA, and vIPAG, indicating that inhibition of PV INs mitigates the impact of chronic stress on stress regulatory brain regions. PV IN inhibition during CVS also attenuated CVS-induced adrenal hypertrophy and body weight loss, further suggesting that PV IN signaling during CVS might be playing a role in somatic effects of chronic stress. Interestingly, PV IN inhibition during the TST, which was the first stressor in the modified CVS paradigm, resulted in an increase in passive coping and a decrease in active coping in stress naive animals. This finding suggests unique mechanisms of PV IN plasticity following acute versus chronic stress paradigms and also implies that an optimum level of prefrontal PV IN activity is important to maintain prefrontal $E / I$ balance so that PFC can respond appropriately to stress. Overall, the data indicate that PV INs play a role in inhibiting IL output during chronic stress, suggesting a potential role in driving ventromedial PFC hypofunction. Exploring the role of PV INs in stress-related disorders is an important research direction for future experiments.

GABAergic PV INs are well positioned to provide strong, fast-spiking inhibitory signals to pyramidal projection neurons in the PFC and reduce network excitability, and therefore could be contributing to chronic stressmediated hypoactivity (Winkelmann et al., 2014; Tremblay et al., 2016; Safari et al., 2017). Our data suggest that PV INs play an important role in chronic stress-mediated inhibition of the IL. Chronic inhibition of IL PV INs during CVS resulted in increased active and decreased passive coping behaviors in FST. A switch to active coping can be interpreted as an adaptive strategy to deal with chronic stress, and drugs that are effective antidepressants in humans typically promote active coping styles and reduce passive coping in the FST in mice (Porsolt et al., 1977; Martí and Armario, 1993). GABA receptor antagonists have been shown to have antidepressant and anxiolytic properties (Bhutada et al., 2010; Mehta et al., 2017; Zanos et al., 2017; Samad et al., 2018). It is known that antidepressants such as fluoxetine and ketamine reduce PV expression in the PFC (Ohira et al., 2013; Zhou et al., 2015; Page and Coutellier, 2019). Moreover, preventing the reduction in PV IN activity leads to loss of antidepressant efficacy, further suggesting that reduced activity of PV INs might be playing a role in therapeutic efficacy of antidepressants (Zhou et al., 2015; Page and Coutellier, 2019). Therefore, based on prior studies and our findings, inhibition of PV INs during chronic stress may lead to more adaptive stress coping strategies and reverse some of the behavioral deficits associated with chronic stress. It is important to note that the effects observed in FST are because of PV IN inhibition and not because of any changes in locomotor activity (Extended Data Fig. 4-1). Additionally, we did not detect any effects on FST because of chronic dosing of $\mathrm{CNO}$ alone, suggesting that repeated $\mathrm{CNO}$ dosing did not alter stress coping behavior (Extended Data Fig. 4-2).

Our experiments revealed that inhibition of PV INs in the IL during stress can attenuate chronic stress-induced decreases in Fos expression in key stress regulatory regions such as the PrL, BLA, and vIPAG following FST (Keedwell et al., 2005; Berton et al., 2007; Vialou et al., 2014). Since we cannot verify direct PV IN modulation of IL projections to these regions, we cannot exclude the possibility that reversal of CVS-related inhibition of Fos induction is because of actions of the IL through other projection systems. Nonetheless, the data suggest that PV IN inhibition reduces inhibitory effects of CVS on IL outflow, permitting drive of downstream structures known to participate in physiological reactivity and stress coping behavior (Maier and Watkins, 2010). Notably, this includes the neighboring PrL, which is not targeted by our DREADD injections and thus has Fos excitability modulated by cortico-cortical connections. Involvement of the PrL is consistent with its prominent role in mediation of coping behavior (Fiore et al., 2015; Johnson et al., 2019; Molendijk and de Kloet, 2019).

PV IN modulation did not prevent CVS-induced changes in Fos in the IL following FST. The Fos data in IL represents an overall change in neuronal activity regardless of where the neurons project to. Thus, it is possible that PV IN modulation might be altering neural activity only in specific circuits, such as the IL-PrL or IL-BLA connections. Indeed, prior studies indicate that neurons projecting from IL to BLA receive strong innervation via PV INs (Marek et al., 2018). Additionally, activity of cortical PV INs is essential for microcircuit operations that correlate with behavioral events (Isomura et al., 2009; Kvitsiani et al., 2013; Kim et al., 2016). Thus PV INs might be affecting PFC microcircuits, thereby acting as a functional unit to synchronize the flow of information between IL-PrL (Courtin et al., 2014b; Kepecs and Fishell, 2014). Therefore, it will be important in the future to explore PV IN mediated plasticity in the specific circuits showing reduced Fos expression following PV IN modulation. It has been shown that chronic inhibition of neurons may also lead to plastic changes, resulting in rebound firing and enhanced excitability/hyperactivity when inhibition is removed (Stemmler and Koch, 1999; Sokolova and Mody, 2008; Wiegert et al., 2017; Purohit et al., 2018). Thus, it is also possible that removal of chronic inhibition of PV INs following CVS might have resulted in hyperactivity of PV INs, leading to reduced Fos expression in IL. CVS also causes a reduction in Fos on exposure to acute stress 
(Ostrander et al., 2009; Moench et al., 2019). Therefore, it is possible that the combined effect of rebound firing and CVS might be masking the Fos effects of chronic PV IN inhibition in the IL.

Repeated inactivation of PV INs during stress attenuated the CVS-induced increase of adrenal weight. The adrenals are highly sensitive to repeated stress, and it is believed that increased adrenal size is linked to cumulative increases in adrenocorticotropic hormone (ACTH) secretion (Ulrich-Lai et al., 2006). Blockade of adrenal hypertrophy suggests that PV INs participate in control of the central limb of HPA axis activation and provides additional confirmation of cumulative efficacy of chronic PV IN inhibition in control of stress endpoints. In contrast to the adrenals, CVS caused equivalent decreases in thymus weight, suggesting either sensitization of glucocorticoid sensitivity or enhanced autonomic activation by CVS, presumably mediated by mechanisms independent of PV INs. Chronic inhibition of PV INs also attenuates CVSinduced reduction in final body weight, suggesting PV IN signaling might also be playing a role in CVS mediated body weight effects.

As part of our design, we assessed the impact of IL PV IN inhibition acutely following the first stressor in our CVS regimen, the TST, which allows for behavioral readouts (duration of struggling, immobility and latency to immobility). Acute inhibition of IL PV INs resulted in decreased active coping (struggling) and increased passive coping (immobility) in the TST. Our data are consistent with a prior study indicating that reduced excitatory synaptic drive onto PV INs is linked to increased stress susceptibility and enhanced helplessness behavior (Perova et al., 2015). These data indicate that PV INs may play a role in driving active coping responses, when an animal with no history of prior stress is exposed to a novel acute stressor such as the TST. Together, these studies suggest that activation of PV INs is required for coping responses to acute stress.

Our results with acute PV IN inhibition are in contrast to the results seen in the FST after chronic PV IN inhibition during a two-week CVS exposure. These data indicate different roles for these neurons in acute versus chronic stress adaptations. Our finding of divergent effects of IN function in PFC is in line with previous studies showing opposing effects on emotionality in acute versus chronic somatostatin (SST) IN inhibition in the PFC (Soumier and Sibille, 2014) and on auditory information processing in acute versus chronic IN inhibition in the auditory cortex (Seybold et al., 2012). Our data suggest that distinct neuronal ensembles and brain circuitry may be involved in modulating acute versus chronic stress-mediated behavioral outcomes. It is also possible that chronic stress may result in plastic changes in the same neuronal ensemble recruited by acute stress, leading to differences in stress response. However, it is not known what specific plasticity in the neural network underlies the emergence of opposing phenotypes following chronic stress and therefore further studies are needed to investigate the mechanisms. Moreover, to fully understand the differences observed here with acute versus chronic stress PV IN modulation, it would be beneficial to determine whether chronic stress is able to modify the potentiating effect of acute inactivation on active coping responses in the TST.

Our acute and chronic PV IN inactivation data also suggest that an optimum level of E/I balance needs to be maintained in the PFC for it to function appropriately and PV INs play a crucial role in maintaining that balance (Ferguson and Gao, 2018). Disruption of the balance can lead to abnormal behavioral endpoints and psychiatric illnesses (Selten et al., 2018; Berg et al., 2019; Page and Coutellier, 2019). Our data on TST agree with prior reports suggesting that reducing activity of PV INs acutely under baseline conditions can lead to a more stress vulnerable passive coping response which might be because of an over excitation of the PFC (Perova et al., 2015). On the other hand, chronic stress can disrupt the E/I balance leading to over inhibition by increasing the activity of PV INs, resulting in maladaptive behavioral outcomes (Page et al., 2019; Page and Coutellier, 2019). The current approach is designed to inhibit the over activation of PV INs in the context of chronic stress exposure. Indeed, our results show that inhibiting the activity of PV INs during stress leads to a more active coping response and attenuates CVS mediated alterations in Fos activation in brain regions controlling emotionality as well as attenuating the effects on body and organ weights in response to CVS.

There are a few caveats to the present study that must be considered in the interpretation of the data. First, the modified CVS paradigm used in this study did not produce the typical behavioral effects seen in FST when using alternative CVS procedures (Ghosal et al., 2017; Wohleb et al., 2018). Initially, we thought that older age and chronic injection stress (the later described previously by Moghaddam and Bolinao, 1994), might have resulted in high rates of immobility in control animals leading to a ceiling effect, hence reducing the window to detect an increase in immobility typically observed after CVS exposure. However, additional control experiments showed CVS did not affect FST behavior in younger mice (Extended Data Fig. 4-3). Additional experiments in control mice showed chronic injection stress and single housing also did not affect behavior in FST (Extended Data Fig. 4-3). These results further lead us to conclude that the lack of effect on FST is because of the exclusion of overnight and extended periods of stress in the modified CVS paradigm in our study. Nevertheless, the paradigm resulted in somatic effects leading to reduced body weight and adrenal hypertrophy, indicating that sustained HPA axis drive only occurred in the CVS group. Moreover, our CVS procedure also reduced Fos activation in stress regulatory brain regions, demonstrating alterations in neuronal activation typically observed following CVS (Ostrander et al., 2009; Moench et al., 2019). Second, although our injection site was primarily in the IL, there was some spread into the PrL and DP area of the cortex ( $28 \%$ of cells). Third, this study was conducted only in male mice because prior research showed CVS mediated alteration in inhibitory synaptic drive in the IL of males (McKlveen et al., 2016, 2019). Because PV IN modulation may have sex specific effects (Shepard et al., 2016; Page et al., 2019), it would be important to examine the effects of PV IN modulation 
during stress in females. Fourth, in this study PV INs were inhibited during the $14 \mathrm{~d}$ of CVS. The degree to which the efficacy of DREADD-mediated inhibition might vary over the course of the 14-d treatment paradigm remains unclear and will require additional study. Finally, in this study we euthanized animals after exposure to one behavioral paradigm (FST) to obtain the anatomic Fos expression dataset to a novel stressor following CVS. Chronic stress can be characterized by cellular and behavioral changes spanning multiple interconnected neural network adaptations which were not explored in our current study. In order to get a clear representation of how PV IN modulation during stress is affecting emotionality, additional behaviors may be worth exploring in follow-up experiments.

Taken together, our data are consistent with a causal role of IL PV INs in initiating and coordinating coping strategies and physiological outcomes in response to stress. Chronic stress-mediated hypoactivity and aberrant behavioral responses may be mediated partly via plastic changes in PV IN function and may play a role in stressrelated pathologies (e.g., depression and PTSD). Our data indicate that chemogenetic inhibition of PV INs during chronic stress, which reduces PV-initiated inhibition in the context of each individual stressor experience, may block or attenuate inhibition of glutamatergic neurons. In this case, maintenance of inhibitory synaptic inputs onto glutamatergic IL projection neurons is sufficient to attenuate some but not all behavioral and physiological consequences of chronic stress exposure, including decreased passive (immobility) and increased active coping behaviors (swimming) in the FST, attenuating CVS effects on reduction in neuronal Fos activity, adrenal hypertrophy, and body weight loss. Our findings suggest that reducing the activity of PV INs in the PFC during chronic stress may facilitate output of prefrontal neurons and could provide therapeutic benefits for stress-related disorders.

In conclusion, this study provides support that PV INs play a role in chronic stress-mediated coping behaviors and physiological phenotypes. Furthermore, the study adds to the current knowledge regarding possible mechanisms of hypoactivity of the PFC and how PV INs may be involved in driving chronic stress-related pathologies. The study also highlights opposing effects of acute and chronic PV IN inhibition, indicating different underlying mechanisms involved in acute versus chronic stress paradigms. Overall, this study shows that reducing PV IN activity to promote prefrontal output may be an effective treatment strategy for stress-related illnesses.

\section{References}

Baldessarini RJ, Centorrino F, Huston Lyons D, Cohen BM, Flood JG, Volpicelli SA (1993) Tissue concentrations of clozapine and its metabolites in the rat. Neuropsychopharmacology 9:117-124.

Berg L, Eckardt J, Masseck OA (2019) Enhanced activity of pyramidal neurons in the infralimbic cortex drives anxiety behavior. PLoS One 14:e0210949.

Berton O, Covington HE, Ebner K, Tsankova NM, Carle TL, Ulery P, Bhonsle A, Barrot M, Krishnan V, Singewald GM, Singewald N, Birnbaum S, Neve RL, Nestler EJ (2007) Induction of $\triangle$ FosB in the periaqueductal gray by stress promotes active coping responses. Neuron 55:289-300.
Bhutada P, Mundhada Y, Bansod K, Ubgade A, Quazi M, Umathe S, Mundhada D (2010) Reversal by quercetin of corticotrophin releasing factor induced anxiety- and depression-like effect in mice. Prog Neuropsychopharmacol Biol Psychiatry 34:955-960.

Burger C, Gorbatyuk OS, Velardo MJ, Peden CS, Williams P, Zolotukhin S, Reier PJ, Mandel RJ, Muzyczka N (2004) Recombinant AAV viral vectors pseudotyped with viral capsids from serotypes 1, 2, and 5 display differential efficiency and cell tropism after delivery to different regions of the central nervous system. Mol Ther 10:302317.

Can A, Dao DT, Terrillion CE, Piantadosi SC, Bhat S, Gould TD (2011) The tail suspension test. J Vis Exp 3769.

Cardin JA, Carlén M, Meletis K, Knoblich U, Zhang F, Deisseroth K, Tsai L-H, Moore Cl (2009) Driving fast-spiking cells induces gamma rhythm and controls sensory responses. Nature 459:663667.

Cearley CN, Wolfe JH (2006) Transduction characteristics of adenoassociated virus vectors expressing cap serotypes 7, 8, 9, and Rh10 in the mouse brain. Mol Ther 13:528-537.

Cotella EM, Gómez AS, Lemen P, Chen C, Fernández G, Hansen C, Herman JP, Paglini MG (2019) Long-term impact of chronic variable stress in adolescence versus adulthood. Prog Neuropsychopharmacol Biol Psychiatry 88:303-310.

Courtin J, Chaudun F, Rozeske RR, Karalis N, Gonzalez-Campo C, Wurtz H, Abdi A, Baufreton J, Bienvenu TCM, Herry C (2014a) Prefrontal parvalbumin interneurons shape neuronal activity to drive fear expression. Nature 505:92-96.

Courtin J, Chaudun F, Rozeske RR, Karalis N, Gonzalez-Campo C, Wurtz H, Abdi A, Baufreton J, Bienvenu TCM, Herry C (2014b) Prefrontal parvalbumin interneurons shape neuronal activity to drive fear expression. Nature 505:92-96.

Cummings KA, Clem RL (2020) Prefrontal somatostatin interneurons encode fear memory. Nat Neurosci 23:61-74.

DeFelipe J, López-Cruz PL, Benavides-Piccione R, Bielza C, Larrañaga $P$, Anderson $S$, Burkhalter $A$, Cauli B, Fairén A, Feldmeyer D, Fishell G, Fitzpatrick D, Freund TF, González-Burgos G, Hestrin S, Hill S, Hof PR, Huang J, Jones EG, Kawaguchi Y, et al. (2013) New insights into the classification and nomenclature of cortical GABAergic interneurons. Nat Rev Neurosci 14:202-216.

Drevets WC, Price JL, Simpson JR, Todd RD, Reich T, Vannier M, Raichle ME (1997) Subgenual prefrontal cortex abnormalities in mood disorders. Nature 386:824-827.

Drevets WC, Price JL, Furey ML (2008) Brain structural and functional abnormalities in mood disorders: implications for neurocircuitry models of depression. Brain Struct Funct 213:93-118.

Duman RS (2014) Pathophysiology of depression and innovative treatments: remodeling glutamatergic synaptic connections. Dialogues Clin Neurosci 16:11-27.

Duman CH, Duman RS (2015) Spine synapse remodeling in the pathophysiology and treatment of depression. Neurosci Lett 601:20-29.

Ferguson BR, Gao WJ (2018) PV interneurons: critical regulators of $\mathrm{E} / \mathrm{l}$ balance for prefrontal cortex-dependent behavior and psychiatric disorders. Front Neural Circuits 12:37.

Fiore VG, Mannella F, Mirolli M, Latagliata EC, Valzania A, Cabib S, Dolan RJ, Puglisi-Allegra S, Baldassarre G (2015) Corticolimbic catecholamines in stress: a computational model of the appraisal of controllability. Brain Struct Funct 220:1339-1353.

Franklin K, Paxinos G (2007) The mouse brain in stereotaxic coordinates. San Diego: Elsevier.

Ghosal S, Packard AEB, Mahbod P, McKlveen JM, Seeley RJ, Myers B, Ulrich-Lai Y, Smith EP, D'Alessio DA, Herman JP (2017) Disruption of glucagon-like peptide 1 signaling in Sim1 neurons reduces physiological and behavioral reactivity to acute and chronic stress. J Neurosci 37:184-193.

Groisman Al, Yang SM, Schinder AF (2020) Differential coupling of adult-born granule cells to parvalbumin and somatostatin interneurons. Cell Rep 30:202-214.e4.

Guettier JM, Gautam D, Scarselli M, De Azua IR, Li JH, Rosemond E, Ma X, Gonzalez FJ, Armbruster BN, Lu H, Roth BL, Wess J (2009) 
A chemical-genetic approach to study $\mathrm{G}$ protein regulation of $\beta$ cell function in vivo. Proc Natl Acad Sci USA 106:19197-19202.

Guilloux JP, Seney M, Edgar N, Sibille E (2011) Integrated behavioral $z$-scoring increases the sensitivity and reliability of behavioral phenotyping in mice: relevance to emotionality and sex. J Neurosci Methods 197:21-31.

Hasler G, Fromm S, Carlson PJ, Luckenbaugh DA, Waldeck T, Geraci M, Roiser JP, Neumeister A, Meyers N, Charney DS, Drevets WC (2008) Neural response to catecholamine depletion in unmedicated subjects with major depressive disorder in remission and healthy subjects. Arch Gen Psychiatry 65:521-531.

Holmes SE, Scheinost D, DellaGioia N, Davis MT, Matuskey D, Pietrzak RH, Hampson M, Krystal JH, Esterlis I (2018) Cerebellar and prefrontal cortical alterations in PTSD: structural and functional evidence. Chronic Stress 2:247054701878639.

Isomura Y, Harukuni R, Takekawa T, Aizawa H, Fukai T (2009) Microcircuitry coordination of cortical motor information in self-initiation of voluntary movements. Nat Neurosci 12:1586-1593.

Jendryka M, Palchaudhuri M, Ursu D, van der Veen B, Liss B, Kätzel D, Nissen W, Pekcec A (2019) Pharmacokinetic and pharmacodynamic actions of clozapine-N-oxide, clozapine, and compound 21 in DREADD-based chemogenetics in mice. Sci Rep 9.

Johnson SB, Emmons EB, Lingg RT, Anderson RM, Romig-Martin SA, Lalumiere RT, Narayanan NS, Viau V, Radley JJ (2019) Prefrontal-bed nucleus circuit modulation of a passive coping response set. 39:1405-1419.

Keedwell PA, Andrew C, Williams SCR, Brammer MJ, Phillips ML (2005) The neural correlates of anhedonia in major depressive disorder. Biol Psychiatry 58:843-853.

Kepecs A, Fishell G (2014) Interneuron cell types are fit to function. Nature 505:318-326.

Kessler RC, Berglund P, Demler O, Jin R, Merikangas KR, Walters EE (2005) Lifetime prevalence and age-of-onset distributions of DSM-IV disorders in the national comorbidity survey replication. Arch Gen Psychiatry 62:593-602.

Kim H, ährlund-Richter S, Wang X, Deisseroth K, Carlén M (2016) Prefrontal parvalbumin neurons in control of attention. Cell 164:208-218.

Kvitsiani D, Ranade S, Hangya B, Taniguchi H, Huang JZ, Kepecs A (2013) Distinct behavioural and network correlates of two interneuron types in prefrontal cortex. Nature 498:363-366.

Lein ES, Hawrylycz MJ, Ao N, Ayres M, Bensinger A, Bernard A, Boe AF, Boguski MS, Brockway KS, Byrnes EJ, Chen L, Chen L, Chen TM, Chin MC, Chong J, Crook BE, Czaplinska A, Dang CN, Datta S, Dee NR, et al. (2007) Genome-wide atlas of gene expression in the adult mouse brain. Nature 445:168-176.

Li N, Liu RJ, Dwyer JM, Banasr M, Lee B, Son H, Li XY, Aghajanian G, Duman RS (2011) Glutamate N-methyl-D-aspartate receptor antagonists rapidly reverse behavioral and synaptic deficits caused by chronic stress exposure. Biol Psychiatry 69:754-761.

Lidster K, Owen K, Browne WJ, Prescott MJ (2019) Cage aggression in group-housed laboratory male mice: an international data crowdsourcing project. Sci Rep 9:15211.

Luscher B, Shen Q, Sahir N (2011) The GABAergic deficit hypothesis of major depressive disorder. Mol Psychiatry 16:383-406.

MacLaren DAA, Browne RW, Shaw JK, Radhakrishnan SK, Khare P, España RA, Clark SD (2016) Clozapine N-oxide administration produces behavioral effects in Long-Evans rats: implications for designing DREADD experiments. eNeuro 3:ENEURO.0219-16.2016.

Maier SF, Watkins LR (2010) Role of the medial prefrontal cortex in coping and resilience. Brain Res 1355:52-60.

Marek R, Jin J, Goode TD, Giustino TF, Wang Q, Acca GM, Holehonnur R, Ploski JE, Fitzgerald PJ, Lynagh T, Lynch JW, Maren S, Sah P (2018) Hippocampus-driven feed-forward inhibition of the prefrontal cortex mediates relapse of extinguished fear. Nat Neurosci 21:384-392.

Martí J, Armario A (1993) Effects of diazepam and desipramine in the forced swimming test: influence of previous experience with the situation. Eur J Pharmacol 236:295-299.
McKlveen JM, Morano RL, Fitzgerald M, Zoubovsky S, Cassella SN, Scheimann JR, Ghosal S, Mahbod P, Packard BA, Myers B, Baccei ML, Herman JP (2016) Chronic stress increases prefrontal inhibition: a mechanism for stress-induced prefrontal dysfunction. Biol Psychiatry 80:754-764.

McKlveen JM, Moloney RD, Scheimann JR, Myers B, Herman JP (2019) "Braking" the prefrontal cortex: the role of glucocorticoids and interneurons in stress adaptation and pathology. Biol Psychiatry 86:669-681.

Mehta V, Parashar A, Udayabanu M (2017) Quercetin prevents chronic unpredictable stress induced behavioral dysfunction in mice by alleviating hippocampal oxidative and inflammatory stress. Physiol Behav 171:69-78.

Moench KM, Breach MR, Wellman CL (2019) Chronic stress produces enduring sex- and region-specific alterations in novel stress-induced c-Fos expression. Neurobiol Stress 10:100147.

Moghaddam B, Bolinao ML (1994) Glutamatergic antagonists attenuate ability of dopamine uptake blockers to increase extracellular levels of dopamine: implications for tonic influence of glutamate on dopamine release. Synapse 18:337-342.

Molendijk ML, de Kloet ER (2019) Coping with the forced swim stressor: current state-of-the-art. Behav Brain Res 364:1-10.

Murray EA, Wise SP, Drevets WC (2011) Localization of dysfunction in major depressive disorder: prefrontal cortex and amygdala. Biol Psychiatry 69:e43-e54.

Musazzi L, Treccani G, Popoli M (2015) Functional and structural remodeling of glutamate synapses in prefrontal and frontal cortex induced by behavioral stress. Front Psychiatry 6:60.

Ohira K, Takeuchi R, Iwanaga T, Miyakawa T (2013) Chronic fluoxetine treatment reduces parvalbumin expression and perineuronal nets in gamma-aminobutyric acidergic interneurons of the frontal cortex in adult mice. Mol Brain 6:43.

Ostrander MM, Ulrich-Lai YM, Choi DC, Flak JN, Richtand NM, Herman JP (2009) Chronic stress produces enduring decreases in novel stress-evoked c-fos mRNA expression in discrete brain regions of the rat. Stress 12:469-477.

Page CE, Coutellier L (2019) Prefrontal excitatory/inhibitory balance in stress and emotional disorders: evidence for over-inhibition. Neurosci Biobehav Rev 105:39-51.

Page CE, Alexander J, Shepard R, Coutellier L (2018) Npas4 deficiency interacts with adolescent stress to disrupt prefrontal GABAergic maturation and adult cognitive flexibility. Genes Brain Behav 17:e12459.

Page CE, Shepard R, Heslin K, Coutellier L (2019) Prefrontal parvalbumin cells are sensitive to stress and mediate anxiety-related behaviors in female mice. Sci Rep 9.

Perova Z, Delevich K, Li B (2015) Depression of excitatory synapses onto parvalbumin interneurons in the medial prefrontal cortex in susceptibility to stress. J Neurosci 35:3201-3206.

Phillips ML, Robinson HA, Pozzo-Miller L (2019) Ventral hippocampal projections to the medial prefrontal cortex regulate social memory. Elife 8:e44182.

Porsolt RD, Le Pichon M, Jalfre M (1977) Depression: a new animal model sensitive to antidepressant treatments. Nature 266:730732.

Purohit K, Parekh PK, Kern J, Logan RW, Liu Z, Huang Y, McClung CA, Crabbe JC, Ozburn AR (2018) Pharmacogenetic manipulation of the nucleus accumbens alters binge-like alcohol drinking in mice. Alcohol Clin Exp Res 42:879-888.

Radley JJ, Rocher AB, Miller M, Janssen WGM, Liston C, Hof PR, McEwen BS, Morrison JH (2006) Repeated stress induces dendritic spine loss in the rat medial prefrontal cortex. Cereb Cortex 16:313-320.

Rogers MA, Kasai K, Koji M, Fukuda R, Iwanami A, Nakagome K, Fukuda M, Kato N (2004) Executive and prefrontal dysfunction in unipolar depression: a review of neuropsychological and imaging evidence. Neurosci Res 50:1-11.

Rymar VV, Sadikot AF (2007) Laminar fate of cortical GABAergic interneurons is dependent on both birthdate and phenotype. $J$ Comp Neurol 501:369-380. 
Safari MS, Mirnajafi-Zadeh J, Hioki H, Tsumoto T (2017) Parvalbumin-expressing interneurons can act solo while somatostatin-expressing interneurons act in chorus in most cases on cortical pyramidal cells. Sci Rep 7:12764.

Samad N, Saleem A, Yasmin F, Shehzad MA (2018) Quercetin protects against stress-induced anxiety- and depression-like behavior and improves memory in male mice. Physiol Res 67:795-808.

Selten M, Van Bokhoven H, Kasri NN (2018) Inhibitory control of the excitatory/inhibitory balance in psychiatric disorders. F1000Res 7:23.

Seybold BA, Stanco A, Cho KKA, Potter GB, Kim C, Sohal VS, Rubenstein JLR, Schreiner CE (2012) Chronic reduction in inhibition reduces receptive field size in mouse auditory cortex. Proc Natl Acad Sci USA 109:13829-13834.

Shepard R, Coutellier L (2018) Changes in the prefrontal glutamatergic and parvalbumin systems of mice exposed to unpredictable chronic stress. Mol Neurobiol 55:2591-2512.

Shepard R, Page CE, Coutellier L (2016) Sensitivity of the prefrontal GABAergic system to chronic stress in male and female mice: relevance for sex differences in stress-related disorders. Neuroscience 332:1-12.

Sherwood CC, Raghanti MA, Stimpson CD, Bonar CJ, de Sousa AA, Preuss TM, Hof PR (2007) Scaling of inhibitory interneurons in areas $\mathrm{v} 1$ and $\mathrm{v} 2$ of anthropoid primates as revealed by calciumbinding protein immunohistochemistry. Brain Behav Evol 69:176195.

Sokolova IV, Mody I (2008) Silencing-induced metaplasticity in hippocampal cultured neurons. J Neurophysiol 100:690-697.

Soumier A, Sibille E (2014) Opposing effects of acute versus chronic blockade of frontal cortex somatostatin-positive inhibitory neurons on behavioral emotionality in mice. Neuropsychopharmacology 39:2252-2262.

Stedehouder J, Brizee D, Shpak G, Kushner SA (2018) Activity-dependent myelination of parvalbumin interneurons mediated by axonal morphological plasticity. J Neurosci 38:3631-3642.

Stemmler M, Koch C (1999) How voltage-dependent conductances can adapt to maximize the information encoded by neuronal firing rate. Nat Neurosci 2:521-527.

Tremblay R, Lee S, Rudy B (2016) GABAergic interneurons in the neocortex: from cellular properties to circuits. Neuron 91:260-292.

Ulrich-Lai YM, Figueiredo HF, Ostrander MM, Choi DC, Engeland WC, Herman JP (2006) Chronic stress induces adrenal hyperplasia and hypertrophy in a subregion-specific manner. Am J Physiol Endocrinol Metab 291:E965-E973.
Veeraiah $\mathrm{P}$, Noronha JM, Maitra S, Bagga $\mathrm{P}$, Khandelwal $\mathrm{N}$, Chakravarty S, Kumar A, Patel AB (2014) Dysfunctional glutamatergic and $\gamma$-aminobutyric acidergic activities in prefrontal cortex of mice in social defeat model of depression. Biol Psychiatry 76:231-238.

Vialou V, Bagot RC, Cahill ME, Ferguson D, Robison AJ, Dietz DM, Fallon B, Mazei-Robison M, Ku SM, Harrigan E, Winstanley CA, Joshi T, Feng J, Berton O, Nestler EJ (2014) Prefrontal cortical circuit for depression- and anxiety-related behaviors mediated by cholecystokinin: role of FosB. J Neurosci 34:3878-3887.

Wiegert JS, Mahn M, Prigge M, Printz Y, Yizhar O (2017) Silencing neurons: tools, applications, and experimental constraints. Neuron 95:504-529.

Winkelmann A, Maggio N, Eller J, Caliskan G, Semtner M, Häussler U, Jüttner R, Dugladze T, Smolinsky B, Kowalczyk S, Chronowska E, Schwarz G, Rathjen FG, Rechavi G, Haas CA, Kulik A, Gloveli T, Heinemann U, Meier JC (2014) Changes in neural network homeostasis trigger neuropsychiatric symptoms. J Clin Invest 124:696711.

Wohleb ES, Terwilliger R, Duman CH, Duman RS (2018) Stressinduced neuronal colony stimulating factor 1 provokes microgliamediated neuronal remodeling and depressive-like behavior. Biol Psychiatry 83:38-49.

Xia F, Richards BA, Tran MM, Josselyn SA, Takehara-Nishiuchi K, Frankland PW (2017) Parvalbumin-positive interneurons mediate neocortical-hippocampal interactions that are necessary for memory consolidation. Elife 6:e27868.

Zanos P, Nelson ME, Highland JN, Krimmel SR, Georgiou P, Gould TD, Thompson SM (2017) A negative allosteric modulator for $\alpha 5$ subunit-containing GABA receptors exerts a rapid and persistent antidepressant-like action without the side effects of the NMDA receptor antagonist ketamine in mice. eNeuro 4:ENEURO.028516.2017.

Zhao ZD, Chen Z, Xiang X, Hu M, Xie H, Jia X, Cai F, Cui Y, Chen Z, Qian L, Liu J, Shang C, Yang Y, Ni X, Sun W, Hu J, Cao P, Li H, Shen WL (2019) Zona incerta GABAergic neurons integrate preyrelated sensory signals and induce an appetitive drive to promote hunting. Nat Neurosci 22:921-932.

Zhou Z, Zhang G, Li X, Liu X, Wang N, Qiu L, Liu W, Zuo Z, Yang J (2015) Loss of phenotype of parvalbumin interneurons in rat prefrontal cortex is involved in antidepressant- and propsychotic-like behaviors following acute and repeated ketamine administration. Mol Neurobiol 51:808-819. 